\title{
Short- and intermediate-term outcomes of hybrid coronary revascularization for double-vessel disease
}

Nirav C. Patel, MD, ${ }^{a}$ Jonathan M. Hemli, MD, ${ }^{a}$ Michael C. Kim, MD, ${ }^{b}$ Karthik Seetharam, MD, ${ }^{a}$ Luigi Pirelli, MD, ${ }^{a}$ Derek R. Brinster, MD, ${ }^{a}$ S. Jacob Scheinerman, MD, ${ }^{a}$ and Varinder P. Singh, MD $^{b}$

\section{ABSTRACT}

Objective: We sought to evaluate midterm survival data and resource use for patients who received hybrid coronary revascularization for 2-vessel coronary disease (robotic-assisted left internal thoracic artery graft to left anterior descending coronary artery (minimally invasive direct coronary artery bypass), coupled with a stent to the circumflex or right coronary artery), compared with a concurrent cohort who had traditional coronary artery bypass grafting.

Methods: A comprehensive retrospective review was undertaken of our prospectively collected database from January 2009 to December 2016. We propensity matched 207 patients who underwent hybrid coronary revascularization for double-vessel disease with patients who underwent coronary artery bypass grafting. Eight-year survival data were obtained from the National Death Index.

Results: Thirty-day mortality was 1 patient $(0.5 \%)$ in each of the hybrid coronary revascularization and coronary artery bypass grafting groups. Eight-year survival for the hybrid coronary revascularization group was 187 of 207 patients $(90.3 \%)$ compared with 182 of 207 patients $(87.9 \%)$ for the coronary artery bypass grafting cohort. End-stage renal disease independently predicted late mortality in all patients (overall hazard ratio, 5.60, $P<.001$; hybrid coronary revascularization hazard ratio, $5.58, P=.002$; coronary artery bypass grafting hazard ratio, 4.59 , $P=.006)$. Female patients who underwent hybrid coronary revascularization had a higher incidence of late death (hazard ratio, 2.47, $P=.05$ ). Length of stay and perioperative transfusion requirements were lower in the hybrid coronary revascularization group $(P<.0001)$.

Conclusions: Hybrid coronary revascularization for double-vessel coronary disease is associated with similar short-term outcomes and intermediate-term survival as traditional coronary artery bypass grafting. Hybrid coronary revascularization is associated with lower transfusion requirements and a shorter length of stay than coronary artery bypass grafting. (J Thorac Cardiovasc Surg 2018;156:1799-807)

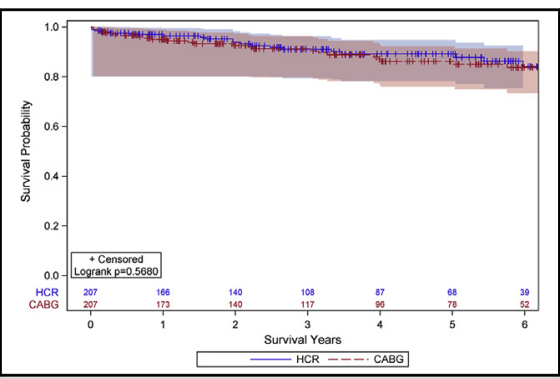

Survival estimates for matched patients who received HCR or CABG for 2-vessel disease.

Central Message

HCR in double-vessel coronary disease has similar short-term outcomes and midterm survival to those of $\mathrm{CABG}$ and uses less perioperative resources.

\section{Perspective}

Intermediate-term survival between the 2 methods of revascularization for double-vessel disease is comparable, as are short-term and in-hospital outcomes. HCR is associated with shorter hospital stay and lower transfusion requirements than traditional CABG.

See Editorial Commentary page 1808.

See Editorial page 1798.
The 5-year results of the SYNergy between percutaneous coronary intervention with TAXUS and Cardiac Surgery

\footnotetext{
From the Departments of a Cardiovascular and Thoracic Surgery and ${ }^{\mathrm{b}} \mathrm{Cardiology}$, Lenox Hill Hospital/Northwell Health, New York, NY.

Date of Institutional Review Board Approval: November 29, 2016. Institutional Review Board Number 16-835.

Read at the 98th Annual Meeting of The American Association for Thoracic Surgery, San Diego, California, April 28-May 1, 2018.

Received for publication Jan 15, 2018; revisions received April 12, 2018; accepted for publication April 17, 2018; available ahead of print Aug 14, 2018.

Address for reprints: Nirav C. Patel, MD, Department of Cardiovascular and Thoracic Surgery, Lenox Hill Hospital, 130 East 77th St, 4th Floor, New York, NY 10075 (E-mail: nipatel@northwell.edu).

$0022-5223 / \$ 36.00$

Copyright (C) 2018 by The American Association for Thoracic Surgery https://doi.org/10.1016/j.jtcvs.2018.04.078
}

(SYNTAX) trial support coronary artery bypass grafting (CABG) as the standard of care for patients with complex anatomy, but suggest that percutaneous coronary intervention (PCI) is an acceptable alternative for patients with less diffuse disease. ${ }^{1,2}$ Repeat revascularization rates are higher after PCI in patients with complex disease, and the

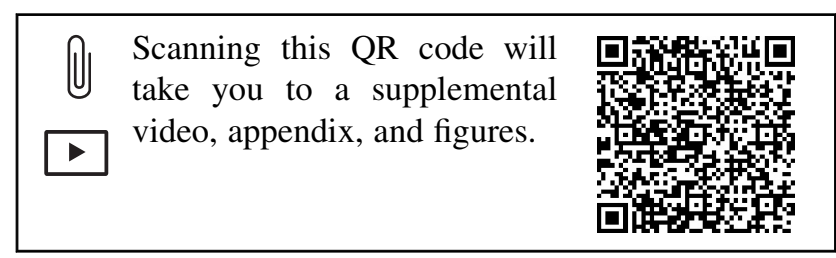




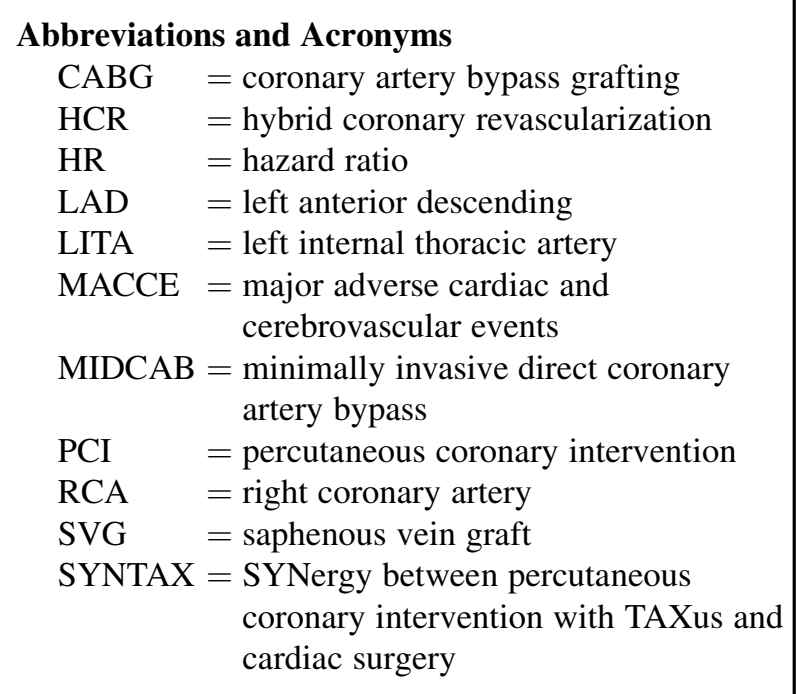

repeat intervention itself is an independent predictor of adverse outcomes. ${ }^{3}$ The Future Revascularization Evaluation in Patients with Diabetes Mellitus: Optimal Management of Multivessel Disease trial determined that CABG was superior to PCI for diabetic patients with advanced coronary disease, with reduced rates of death and myocardial infarction. ${ }^{4}$ Although the role of CABG thus seems clear in patients with complex multivessel disease, the algorithm becomes more ambiguous for those with less diffuse stenoses.

The 2012 American College of Cardiology Foundation/ American Heart Association/American College of Physicians/American Association for Thoracic Surgery/Preventive Cardiovascular Nurses Association/Society for Cardiovascular Angiography and Interventions/Society of Thoracic Surgeons Guideline for the Diagnosis and Management of Patients with Stable Ischemic Heart Disease offers a Class IIb recommendation that hybrid coronary revascularization (HCR) may be a "reasonable alternative" to CABG or multivessel PCI, in an attempt to "improve the risk-benefit ratio of the procedures," a somewhat vague statement. The 2014 European Society of Cardiology/European Association for Cardio-Thoracic Surgery Guidelines on Myocardial Revascularization mentions HCR as an option only when multivessel PCI is deemed to be unsuitable or when $\mathrm{CABG}$ is considered to be at prohibitive risk, as well as in some special circumstances. ${ }^{6}$ A recent analysis from the Society of Thoracic Surgeons Adult Cardiac Surgery Database revealed that HCR represented only $0.48 \%$ of all CABG volume in the United States between 2011 and 2013. ${ }^{7}$ Despite being primarily used in patients with higher baseline risk profiles, there were no significant differences observed in the composite end point of in- hospital mortality and major perioperative morbidity when HCR was compared with CABG.

The optimal technique of revascularization for patients with lower to intermediate SYNTAX scores is yet to be determined. We evaluated the intermediate-term survival of these patients undergoing HCR to better elucidate the role of this therapy, particularly in the current era of newer-generation drug-eluting stents. We focused our analysis on patients with 2-vessel coronary disease, so as not to encroach on that patient population with advanced multivessel disease who have been addressed in multiple other studies. $^{5-7}$

\section{PATIENTS AND METHODS \\ Study Population and Definitions}

A review was undertaken of all patients who underwent surgical myocardial revascularization at Lenox Hill Hospital/Northwell Health between January 2009 and December 2016. Of these patients, those who had intervention for double-vessel disease were selected for analysis.

Double-vessel disease was defined as significant stenosis in the left anterior descending (LAD) coronary artery, coupled with a lesion(s) requiring intervention in the circumflex or right coronary artery (RCA). Patients with isolated left main stenosis were included in our analysis, because these cases required grafts to both the LAD and the circumflex artery and were thus functionally equivalent to 2 -vessel disease.

Indications for HCR were the presence of significant disease in the LAD, with a suitable distal target vessel for grafting, and a circumflex or RCA lesion deemed amenable to PCI. The relative contraindications to HCR were the need for emergency revascularization or severe pulmonary disease rendering the patient unable to tolerate single-lung ventilation. Other investigators have tended not to offer HCR to patients who are morbidly obese, ${ }^{8}$ but we did not withhold HCR from these patients. Our experience with minimally invasive robotic-assisted left internal thoracic artery (LITA)-LAD grafting (minimally invasive direct coronary artery bypass $[\mathrm{MIDCAB}]$ ) in obese patients has been reported. ${ }^{9}$

We analyzed 207 propensity-matched pairs of patients who underwent HCR or CABG for double-vessel disease. Patients who underwent surgery for single-vessel or triple-vessel disease were excluded. Any patients who required concomitant noncoronary surgery, in addition to their revascularization procedure, were also excluded, as were hemodynamically unstable patients, patients who required emergency or salvage surgery, and patients who underwent prior cardiac or thoracic surgery. This study was conducted with the approval of the Northwell Health Institutional Review Board.

\section{Surgical and Procedural Details}

For patients undergoing HCR, we prefer a MIDCAB-first approach, followed by interval PCI. This strategy allows the surgical revascularization to be performed without concern for potential bleeding that may be associated with dual antiplatelet therapy. Nevertheless, we have previously described our satisfactory experience with MIDCAB in patients taking dual antiplatelet agents, ${ }^{10}$ results not necessarily echoed by others. ${ }^{11}$ Of note, the MIDCAB-first approach also allows the LITA-LAD graft to be interrogated during the subsequent $\mathrm{PCI}$ procedure.

A PCI-first strategy was pursued in those patients who presented with an acute coronary syndrome in which the non-LAD vessel was deemed to be the culprit lesion or in those patients in whom the angiographic severity and clinical import of the non-LAD lesion were thought to be greater than the LAD itself. For these patients, subsequent LITA-LAD grafting was performed on dual antiplatelet therapy.

Our technique for robotic-assisted MIDCAB has been described. ${ }^{12,13}$ Briefly, the da Vinci Intuitive robot system (Intuitive Surgical Inc, 


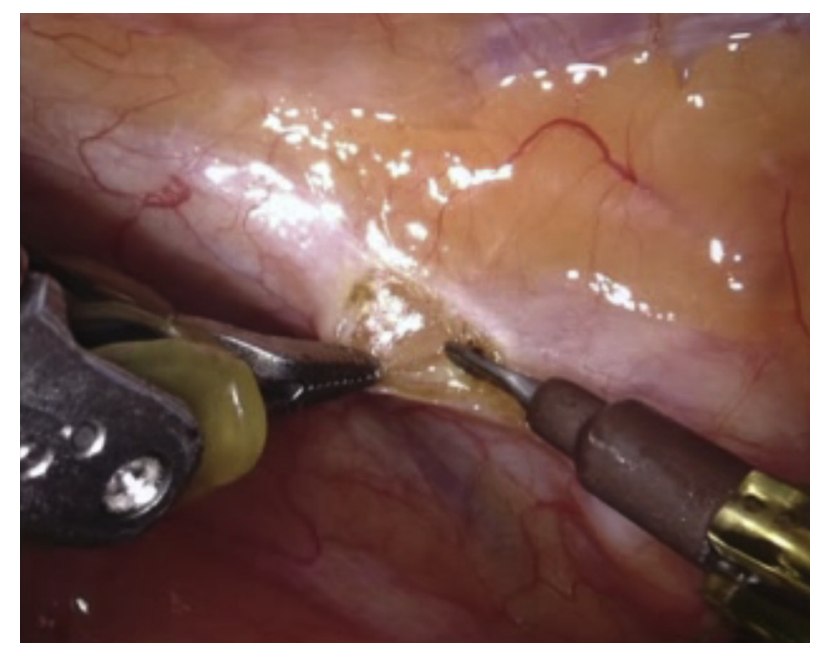

VIDEO 1. Illustrative case of HCR in a patient with double-vessel disease, incorporating robotic-assisted LITA-LAD MIDCAB, followed by interval PCI to the left circumflex. $H C R$, Hybrid coronary revascularization; $L A D$, left anterior descending coronary artery; LITA, left internal thoracic artery; $M I D C A B$, minimally invasive direct coronary artery bypass; $P C I$, percutaneous coronary intervention. Video available at: https://www.jtcvs.org/ article/S0022-5223(18)31216-9/fulltext.

Sunnyvale, Calif) was used to facilitate LITA harvest. The LITA-LAD anastomosis was completed off-pump, through an anterior muscle-sparing, nonrib-spreading minithoracotomy, with the assistance of a low-profile compression myocardial stabilization device (Video 1). An intracoronary shunt was used in all cases. Graft flow and patency were routinely assessed in the operating room using the Medistim VeriQ transit-time flow measurement system (Medistim USA Inc, Plymouth, Minn).

The PCI component of the HCR cases was performed using standard techniques, the majority of patients receiving drug-eluting stents. We did not hesitate to offer HCR to patients who required complex PCI (as defined by the National Cardiovascular Data Registry) CathPCI Registry: https:// www.ncdr.com/WebNCDR/docs/default-source/public-data-collectiondocuments/cathpci_v4_codersdictionary_4-4.pdf?sfvrsn=2.

The majority of our sternotomy CABG cases were completed off-pump, our technique for which has been reported. ${ }^{14,15}$ After conduit harvest, the LITA-LAD anastomosis was almost invariably completed first. Suction myocardial positioning and stabilization devices were used to aid in target vessel exposure, coupled with other standard off-pump techniques. Once again, intracoronary shunts were routinely used in all cases. Proximal anastomoses were performed before or after the distal anastomoses, using a variety of techniques. As in our MIDCAB cases, all grafts were assessed using transit-time flow measurement before the administration of protamine.

\section{Data Analysis}

Definitions of patient demographic characteristics, perioperative variables, and postoperative outcomes were obtained from the New York State Cardiac Surgery Reporting System (https://www.health.ny.gov/ forms/cardiac_surgery) and the Society of Thoracic Surgeons Adult Cardiac Surgery Database (http://www.sts.org/registries-research-center/ sts-national-database/adult-cardiac-surgery-database/data-collection).

Study data were collected and managed using Research Electronic Data Capture electronic data capture tools hosted at Lenox Hill Hospital. ${ }^{16}$ Research Electronic Data Capture is a secure, web-based application designed to support data capture for research studies, providing (1) an intuitive interface for validated data entry; (2) audit trails for tracking data manipulation and export procedures; (3) automated export procedures for seamless data downloads to common statistical packages; and (4) procedures for importing data from external sources.

Observed covariates at baseline included age, gender, body mass index, diabetes mellitus, cerebrovascular disease, chronic lung disease, dyslipidemia, hypertension, peripheral artery disease, dialysis-dependent renal failure, history of myocardial infarction, heart failure, and left ventricular ejection fraction. To control for these confounding influences, we calculated propensity scores (or the probability of assignment to HCR or $\mathrm{CABG}$ ) using multivariable logistic regression for each patient. Patients who underwent HCR were matched with patients who underwent

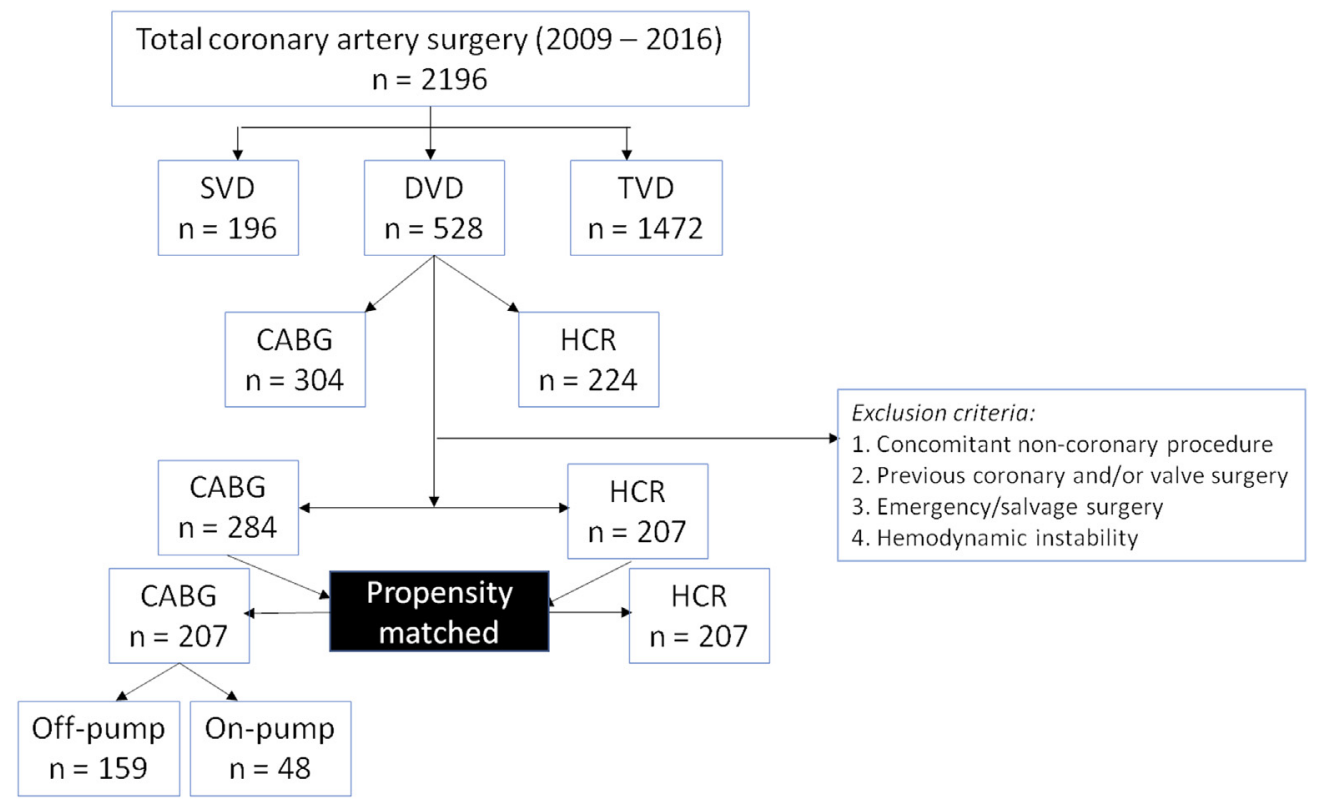

FIGURE 1. Flow chart of patient selection. $S V D$, Single-vessel disease; $D V D$, double-vessel disease; $T V D$, triple-vessel disease; $C A B G$, coronary artery bypass grafting; $H C R$, hybrid coronary revascularization. 
TABLE 1. Baseline patient characteristics

\begin{tabular}{|c|c|c|c|c|c|c|}
\hline \multirow[b]{2}{*}{ Variable } & \multicolumn{3}{|c|}{ Nonmatched groups } & \multicolumn{3}{|c|}{ Propensity-matched groups } \\
\hline & $\overline{\operatorname{HCR}(n=224)}$ & CABG $(n=304)$ & $P$ value & $\overline{\operatorname{HCR}(n=207)}$ & CABG $(n=207)$ & $P$ value \\
\hline Age, $y$, mean \pm SD & $65 \pm 11$ & $66 \pm 11$ & .34 & $65 \pm 11$ & $65 \pm 11$ & .92 \\
\hline Female gender, $\mathrm{n}(\%)$ & $61(27.2)$ & $73(24.0)$ & .36 & $61(29.9)$ & $60(29.4)$ & 1 \\
\hline Body mass index, $\mathrm{kg} / \mathrm{m}^{2}$, mean $\pm \mathrm{SD}$ & $27.4 \pm 4.5$ & $28.7 \pm 5.4$ & .005 & $28.0 \pm 4.5$ & $28.4 \pm 4.7$ & .42 \\
\hline Diabetes mellitus, n (\%) & $106(47.3)$ & $144(47.4)$ & .93 & $97(46.9)$ & $95(45.9)$ & .92 \\
\hline Cerebrovascular disease, $\mathrm{n}(\%)$ & $18(8.0)$ & $38(12.5)$ & .12 & $15(7.2)$ & $18(8.7)$ & .85 \\
\hline Chronic lung disease, n (\%) & $12(5.4)$ & $16(5.3)$ & 1 & $11(5.3)$ & $7(3.4)$ & .47 \\
\hline Dyslipidemia, n (\%) & $164(73.2)$ & $213(70.1)$ & .27 & $157(75.8)$ & $147(71.0)$ & .32 \\
\hline Hypertension, n (\%) & $182(81.3)$ & $236(77.6)$ & .17 & $175(84.5)$ & $164(79.2)$ & .20 \\
\hline Peripheral artery disease, $\mathrm{n}(\%)$ & $35(15.6)$ & $34(11.2)$ & .12 & $30(14.5)$ & $23(11.1)$ & .38 \\
\hline Dialysis-dependent renal failure, $\mathrm{n}(\%)$ & $14(6.3)$ & $9(3.0)$ & .08 & $12(5.8)$ & $9(4.3)$ & .66 \\
\hline Previous myocardial infarction, $\mathrm{n}(\%)$ & $81(36.2)$ & $134(44.1)$ & .10 & $73(35.3)$ & $88(42.5)$ & .16 \\
\hline Heart failure (NYHA III/IV), n (\%) & $36(16.1)$ & $50(16.4)$ & 1 & $33(15.9)$ & $32(15.5)$ & .5 \\
\hline $\operatorname{LVEF} \%$, mean $\pm \mathrm{SD}$ & $52.3 \pm 11.6$ & $50.5 \pm 11.7$ & .08 & $52.5 \pm 11.7$ & $52.3 \pm 11.0$ & 1 \\
\hline
\end{tabular}

$H C R$, Hybrid coronary revascularization; $C A B G$, coronary artery bypass grafting; $S D$, standard deviation; $N Y H A$, New York Heart Association; $L V E F$, left ventricular ejection fraction.

conventional $\mathrm{CABG}$ in a 1:1 ratio through a nearest neighbor-matching algorithm. To exclude bad matches, we instituted a caliper of 0.2 of the standard deviation of the logit of the propensity score. The area under the curve for the receiver operating characteristic of the propensity model was 0.804 . The matched sample included a total of 414 patients evenly distributed in the HCR and CABG groups (Figures E1-E4).

Longitudinal outcomes and survival to 8 years were estimated using Kaplan-Meier analysis and Cox proportional hazard regression. Patient characteristics and outcomes were compared using chi-square, Fisher exact test, Student $t$ test, or Wilcoxon Mann-Whitney test, as appropriate. A chisquare test was used for categoric variables with an expected value for each cell of 5 or greater; if this assumption was not met, then we used the Fisher exact test. Statistical analyses were performed with the IBM Statistical Package for the Social Sciences for Windows, version 22.0 (IBM Corporation, Armonk, NY).

Mean ( \pm standard error of the mean) follow-up was $7.14 \pm 0.121$ years for all patients. All-cause mortality up to a maximum of 8 years was obtained by querying the National Death Index to determine dates of death up to December 31, 2016.

\section{RESULTS}

\section{Patient Characteristics}

Over the study period, a total of 2196 patients underwent coronary artery surgery at our institution. Of these,
528 patients $(24.0 \%)$ had double-vessel disease, of whom $224(42.4 \%)$ underwent HCR, whereas the remaining 304 had surgery via sternotomy. Our study population comprised 207 propensity-matched pairs of patients who underwent HCR or CABG for double-vessel disease (Figure 1). Preoperative patient demographics are summarized in Table 1.

\section{Coronary Anatomy}

The proportion of patients who had left main stenosis in each group was similar. A higher percentage of patients who underwent HCR had RCA stenosis as their target non-LAD lesion than those patients who underwent CABG (37.2\% vs $21.7 \%, P=.0008)$, whereas the inverse was true for the circumflex artery $(62.8 \%$ vs $78.3 \%, P=.0008)$ (Table 2$)$.

The HCR group had a slightly higher SYNTAX score than the CABG group $(20.4 \pm 4.3$ vs $18.0 \pm 4.0$, $P=.019)$. This difference in the anatomic complexity of the diseased vessels was largely mitigated when clinical factors were incorporated into the algorithm; calculation of the SYNTAX score II proved similar for both groups,

TABLE 2. Coronary anatomy

\begin{tabular}{lccc}
\hline \multicolumn{1}{c}{ Variable } & HCR $(\mathbf{n}=\mathbf{2 0 7})$ & CABG $(\mathbf{n}=\mathbf{2 0 7})$ & $\boldsymbol{P}$ value \\
\hline Left main stenosis, $\mathrm{n}(\%)$ & $29(14.0)$ & $24(11.6)$ & .56 \\
Right coronary stenosis, $\mathrm{n}(\%)$ & $77(37.2)$ & $45(21.7)$ & .0008 \\
Circumflex stenosis, $\mathrm{n}(\%)$ & $130(62.8)$ & $162(78.3)$ & .0008 \\
SYNTAX score, mean \pm SD & $20.4 \pm 4.3$ & $18.0 \pm 4.0$ & .019 \\
SYNTAX score II (CABG), mean \pm SD & $29.0 \pm 12.1$ & $29.6 \pm 12.5$ & .99 \\
SYNTAX score II (PCI), mean \pm SD & $34.3 \pm 11.8$ & $32.1 \pm 11.9$ & .97 \\
Residual SYNTAX score & $2.9 \pm 3.4$ & $2.5 \pm 3.0$ & .12 \\
\hline
\end{tabular}

HCR, Hybrid coronary revascularization; $C A B G$, coronary artery bypass grafting; SYNTAX, SYNergy between percutaneous coronary intervention with TAXus and cardiac surgery; $S D$, standard deviation; $P C I$, percutaneous coronary intervention. 
TABLE 3. Procedure characteristics

\begin{tabular}{|c|c|c|}
\hline Variable & $\begin{array}{c}\text { HCR } \\
(\mathrm{n}=\mathbf{2 0 7})\end{array}$ & $\begin{array}{c}\text { CABG } \\
(n=207)\end{array}$ \\
\hline $\begin{array}{l}\text { STS predicted risk of mortality, } \% \text {, } \\
\text { median (IQR)* }\end{array}$ & $1.0(0.5-1.9)$ & $0.8(0.4-1.6)$ \\
\hline No. of distal anastomoses, mean \pm SD & - & $2.2 \pm 0.4$ \\
\hline $\mathrm{CPB}$ time, min, mean $\pm \mathrm{SD} \dagger$ & - & $88.7 \pm 24.6$ \\
\hline Crossclamp time, min, mean $\pm \mathrm{SD}^{\dagger}$ & - & $63.1 \pm 25.0$ \\
\hline Complex PCI, n $(\%) \ddagger$ & $90(43.5)$ & - \\
\hline \multicolumn{3}{|l|}{ Stents used in PCI $\S$} \\
\hline Bare metal, n (\%) & $9(4.3)$ & - \\
\hline Sirolimus-eluting, n (\%) & $1(0.5)$ & - \\
\hline Paclitaxel-eluting, n (\%) & $11(5.3)$ & - \\
\hline Resolute zotarolimus-eluting, n (\%) & $94(45.4)$ & - \\
\hline Endeavor zotarolimus-eluting, n (\%) & $9(4.3)$ & - \\
\hline Everolimus-eluting, n ( $\%)$ & $69(33.3)$ & - \\
\hline Other, n $(\%)$ & $4(1.9)$ & - \\
\hline
\end{tabular}

HCR, Hybrid coronary revascularization; $C A B G$, coronary artery bypass grafting; $S T S$, Society of Thoracic Surgeons; $I Q R$, interquartile range; $S D$, standard deviation; $C P B$, cardiopulmonary bypass; $P C I$, percutaneous coronary intervention. *Predicted risk of mortality based on the STS Adult Cardiac Surgery Database, version 2.81. $\dagger$ Data applicable to on-pump CABG cases only $(n=48)$. $\ddagger$ A high-risk lesion, requiring complex PCI, is defined by the National Cardiovascular Data Registry CathPCI registry as having 1 or more of the following characteristics: diffuse length $(>2 \mathrm{~cm})$, excessive tortuosity of proximal segment, extremely angulated segments more than 90 degrees, total occlusions more than 3 months old or bridging collaterals, inability to protect major side branches, and degenerated vein grafts with friable lesions. $§$ Data incomplete in 10 patients.

irrespective of whether it was with a view to CABG or PCI. There was no difference in the residual SYNTAX score between the 2 patient groups, reflective of the completeness of revascularization achieved in both cohorts.

\section{Procedural Information}

Of the 207 patients who underwent HCR, the majority (142 patients, 68.6\%) had LITA-LAD revascularization first; PCI of the non-LAD vessel was undertaken during a subsequent procedure. One patient $(0.7 \%)$ in this MIDCAB-first group required intraoperative conversion to sternotomy during robotic-assisted LITA harvesting and ended up with a 2-vessel CABG; this patient was retained within the HCR cohort for analysis on an intention-totreat basis.

In these 142 patients, interrogation of the LITA graft during the interval PCI procedure identified 5 grafts $(3.5 \%)$ as having a significant stenosis at the LITA-LAD anastomosis, 3 of which were able to be managed by ballooning techniques with excellent angiographic results. Two patients $(1.4 \%)$ had atretic or occluded LITA grafts that were not amenable to salvage by PCI; both of these patients required reoperative surgery. Patency of the LITA-LAD graft (Fitzgibbon A) was $96.5 \%$ when assessed during the PCI procedure.

A PCI-first approach was adopted in $65 \mathrm{HCR}$ cases $(31.4 \%)$. Of this group, 18 patients $(27.7 \%)$ underwent a repeat coronary angiogram subsequent to their LITA-LAD graft, and the LITA graft was found to be patent in all cases. Surgical and interventional details for each group are summarized in Table 3.

In the CABG group, an internal thoracic artery graft was used to graft the LAD in the majority of cases; 3 patients received a saphenous vein graft $(S V G)$ to the $L A D$, and 1 patient received a free radial artery graft to the LAD. In patients with LAD and circumflex disease, an internal thoracic artery graft was used to revascularize the

TABLE 4. Short-term outcomes

\begin{tabular}{|c|c|c|c|}
\hline Variable & $\operatorname{HCR}(n=207)$ & CABG $(n=207)$ & $P$ value \\
\hline 30-d mortality, n (\%) & $1(0.5)$ & $1(0.5)$ & 1 \\
\hline Stroke, $\mathrm{n}(\%)$ & $1(0.5)$ & $2(1.0)$ & 1 \\
\hline Perioperative myocardial infarction, $\mathrm{n}(\%)$ & $0(0)$ & $1(0.5)$ & 1 \\
\hline Unplanned cardiac reintervention, $\mathrm{n}(\%)$ & $1(0.5)$ & $2(1.0)$ & 1 \\
\hline Bleeding requiring reoperation, $\mathrm{n}(\%)$ & $9(4.3)$ & $7(3.4)$ & .80 \\
\hline Deep sternal infection, $\mathrm{n}(\%)$ & - & $0(0)$ & - \\
\hline Renal failure, $\mathrm{n}(\%)$ & $1(0.5)$ & $4(1.9)$ & .37 \\
\hline Prolonged ventilation $(>24 \mathrm{~h}), \mathrm{n}(\%)$ & $8(3.9)$ & $7(3.4)$ & 1 \\
\hline Sepsis of any cause, n (\%) & $1(0.5)$ & $3(1.4)$ & .62 \\
\hline Gastrointestinal bleeding, $\mathrm{n}(\%)$ & $2(1.0)$ & $4(1.9)$ & .69 \\
\hline $\mathrm{RBC}$ transfusion, $\mathrm{n}(\%)$ & $29(14.0)$ & $59(28.5)$ & $<.0001$ \\
\hline Platelet transfusion, $\mathrm{n}(\%)$ & $8(3.9)$ & $18(8.7)$ & .04 \\
\hline Total hospital stay, $\mathrm{d}$, mean $\pm \mathrm{SD}$ & $7.1 \pm 8.0$ & $8.4 \pm 5.7$ & $<.0001$ \\
\hline Total hospital stay, d, median (IQR) & $5(4$ to 8$)$ & $7(5$ to 9$)$ & - \\
\hline Postoperative hospital stay, $\mathrm{d}$, mean $\pm \mathrm{SD}$ & $5.7 \pm 7.6$ & $6.4 \pm 5.0$ & $<.0001$ \\
\hline Postoperative hospital stay, d, median (IQR) & $5(3$ to 6$)$ & $5(4$ to 6$)$ & - \\
\hline
\end{tabular}

HCR, Hybrid coronary revascularization; $C A B G$, coronary artery bypass grafting; $R B C$, red blood cells; $S D$, standard deviation; $I Q R$, interquartile range. 

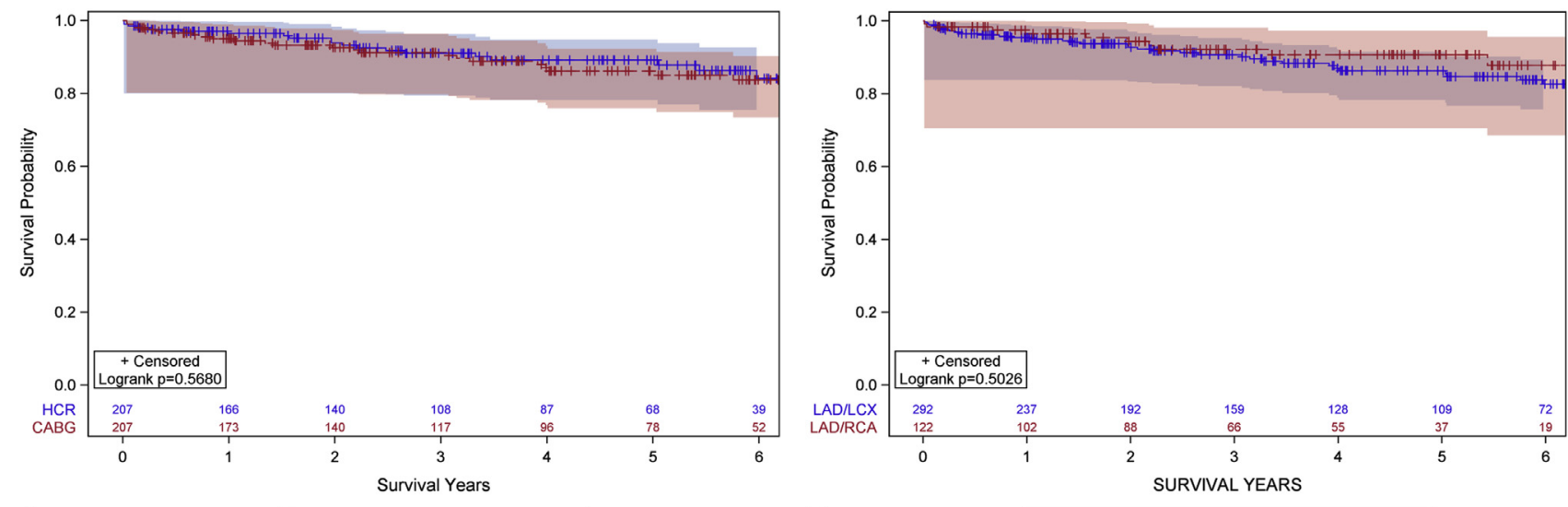

A

B
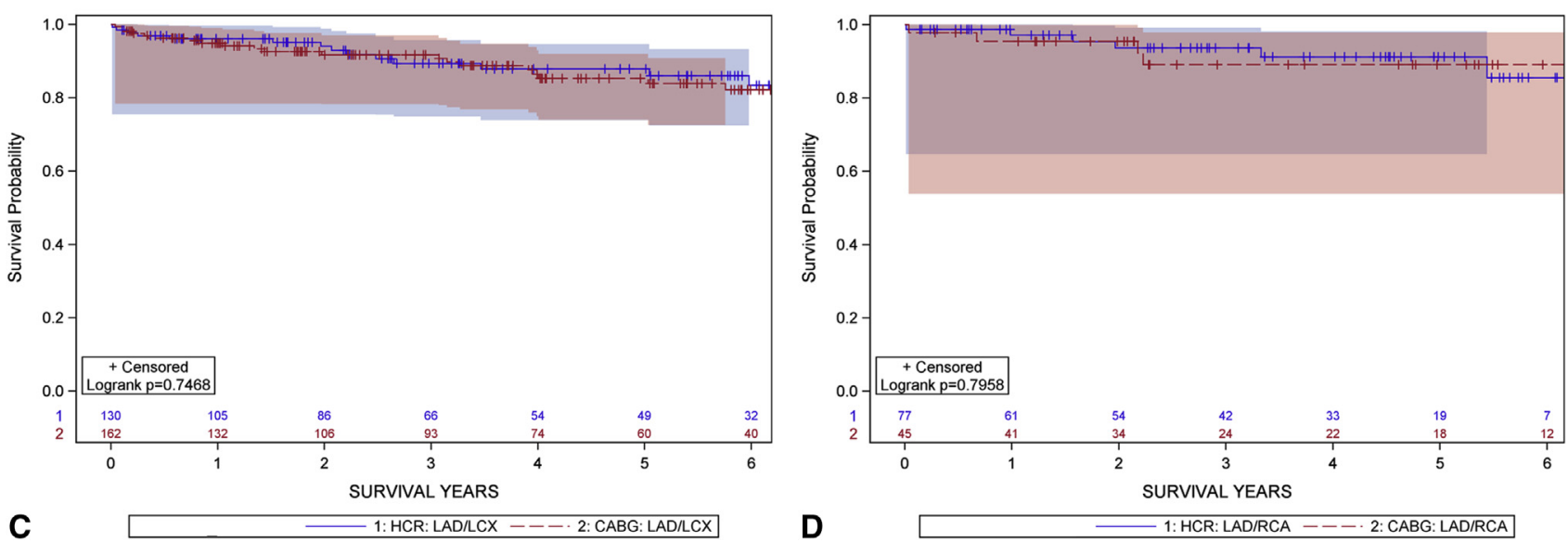

C

FIGURE 2. Kaplan-Meier survival estimates with number of subjects at risk and $95 \%$ Hall-Wellner Bands. A, HCR versus CABG (all patients). B, LAD/ circumflex versus LAD/RCA disease (all patients). C, HCR versus CABG (LAD/circumflex disease). D, HCR versus CABG (LAD/RCA disease). HCR, Hybrid coronary revascularization; $C A B G$, Coronary artery bypass grafting; $L A D$, left anterior descending; $L C x$, (left) circumflex; $R C A$, right coronary artery.

circumflex or 1 of its branches 36 times, an SVG was used in 114 occasions, and a radial artery was used 23 times. In those who had LAD and RCA disease, the RCA territory was grafted by an internal thoracic artery graft 3 times, by an SVG 38 times, and by a radial artery in 4 cases.

\section{Perioperative Outcomes}

The 30-day mortality was $0.5 \%$ in both the HCR and CABG groups ( 1 death in each). There were no differences between the 2 groups with respect to the incidence of stroke and perioperative myocardial infarction, or the need for an unplanned cardiac reintervention (Table 4). There was no difference in the proportion of patients in either group who required ventilation for more than 24 hours.

\section{Intermediate-Term Survival}

No differences in midterm survival were evident, regardless of coronary anatomy or strategy of revascularization (Figure 2). Eight-year survival was $90.3 \%$ for the HCR group (20 deaths) versus $87.9 \%$ for the CABG group (25 deaths). Eight-year survival was $90.2 \%$ for those patients who had LAD and circumflex disease versus $88.7 \%$ for those who had LAD and RCA disease, irrespective of how the lesions were treated. Those patients who had their LAD and circumflex disease managed by HCR had an 8 -year survival of $89.3 \%$, compared with $88.2 \%$ for those with similar anatomy who underwent CABG. Eight-year survival was $92.1 \%$ for those with LAD and RCA disease who received HCR versus $87.0 \%$ for those patients who received $\mathrm{CABG}$.

Increasing age was identified as an independent risk factor for late mortality in all patients, irrespective of their strategy of myocardial revascularization (Table 5). Female gender was a predictor for late death among HCR cases (hazard ratio [HR], 2.47; $P=.05$ ), but not for those patients who underwent CABG. End-stage renal disease was strongly predictive of late mortality across all patient cohorts (HR [all patients], 5.60, $P<.0001$; HR (HCR), 5.58, $P=.002$; HR (CABG), 4.59, $P=.006$ ).

Improved left ventricular ejection fraction was protective against late death in all patient groups. SYNTAX score II (for PCI) was associated with an increased risk of late death 
TABLE 5. Predictors of late mortality

\begin{tabular}{|c|c|c|c|c|}
\hline Variable & HR $(95 \%$ CI $)$ & $P$ value & OR $(95 \%$ CI $)$ & $P$ value \\
\hline \multicolumn{5}{|l|}{ All patients } \\
\hline Age & $1.08(1.04-1.11)$ & $<.0001$ & $1.08(1.04-1.12)$ & $<.0001$ \\
\hline Female gender & $1.59(0.85-2.98)$ & .15 & $2.02(0.96-4.30)$ & .07 \\
\hline LVEF \%* & $0.95(0.93-0.97)$ & $<.0001$ & $0.94(0.91-0.96)$ & $<.0001$ \\
\hline Peripheral artery disease & $1.70(0.84-3.46)$ & .14 & $2.02(0.86-4.70)$ & .11 \\
\hline Diabetes mellitus & $1.52(0.81-2.85)$ & .19 & $1.24(0.60-2.66)$ & .57 \\
\hline End-stage renal disease & $5.60(2.71-11.57)$ & $<.0001$ & $7.29(2.91-18.25)$ & $<.0001$ \\
\hline SYNTAX score & $1(0.93-1.09)$ & .93 & $0.96(0.84-1.09)$ & .52 \\
\hline SYNTAX score II (CABG) & $1.01(0.98-1.05)$ & .42 & $1.00(0.95-1.04)$ & .83 \\
\hline SYNTAX score II (PCI) & $1.08(1.05-1.12)$ & $<.0001$ & $1.09(1.04-1.15)$ & .001 \\
\hline \multicolumn{5}{|l|}{$\operatorname{HCR}(\mathrm{n}=207)$} \\
\hline Age & $1.07(1.02-1.18)$ & .005 & $1.08(1.03-1.14)$ & .004 \\
\hline Female gender & $2.47(1.02-5.60)$ & .05 & $3.39(1.20-9.66)$ & .02 \\
\hline LVEF \%* & $0.97(0.94-1.00)$ & .09 & $0.95(0.91-0.99)$ & .02 \\
\hline Peripheral artery disease & $1.54(0.58-4.15)$ & .39 & $1.65(0.51-5.37)$ & .41 \\
\hline Diabetes mellitus & $1.13(0.46-2.77)$ & .79 & $0.84(0.30-2.41)$ & .75 \\
\hline End-stage renal disease & $5.58(1.90-16.34)$ & .002 & $5.78(1.50-22.24)$ & .01 \\
\hline Complex PCI & $1.56(0.65-3.77)$ & .32 & $0.47(0.16-1.40)$ & .18 \\
\hline SYNTAX score & $0.96(0.85-1.08)$ & .46 & $0.87(0.73-1.03)$ & .11 \\
\hline SYNTAX score II (CABG) & $0.99(0.94-1.05)$ & .78 & $0.98(0.92-1.04)$ & .64 \\
\hline SYNTAX score II (PCI) & $1.07(1.02-1.13)$ & .009 & $1.10(1.03-1.17)$ & .003 \\
\hline \multicolumn{5}{|l|}{$\mathrm{CABG}(\mathrm{n}=207)$} \\
\hline Age & $1.09(1.04-1.14)$ & .001 & $1.09(1.03-1.15)$ & .003 \\
\hline Female gender & $1.20(0.42-3.42)$ & .73 & $1.37(0.42-4.50)$ & .60 \\
\hline LVEF \%* & $0.93(0.90-0.96)$ & $<.0001$ & $0.92(0.88-0.96)$ & $<.0001$ \\
\hline Peripheral artery disease & $1.46(0.46-4.68)$ & .52 & $3.23(0.81-12.83)$ & .10 \\
\hline Diabetes mellitus & $1.94(0.76-4.94)$ & .16 & $1.95(0.67-5.71)$ & .22 \\
\hline End-stage renal disease & $4.59(1.55-13.61)$ & .006 & $8.86(2.21-35.54)$ & .002 \\
\hline Multiple arterial grafts & $0.51(0.22-1.17)$ & .11 & $1.09(0.35-3.32)$ & .89 \\
\hline SYNTAX score & $1.10(0.97-1.24)$ & .16 & $1.11(0.86-1.43)$ & .41 \\
\hline SYNTAX score II (CABG) & $1.03(0.99-1.08)$ & .14 & $1.03(0.95-1.13)$ & .46 \\
\hline SYNTAX score II (PCI) & $1.09(1.05-1.14)$ & $<.0001$ & $1.08(0.99-1.18)$ & .10 \\
\hline
\end{tabular}

HR, Hazard ratio; $C I$, confidence interval; $O R$, odds ratio; $L V E F$, left ventricular ejection fraction; SYNTAX, SYNergy between percutaneous coronary intervention with TAXus and cardiac surgery; $C A B G$, coronary artery bypass grafting; $P C I$, percutaneous coronary intervention; $H C R$, hybrid coronary revascularization. $*$ Increasing LVEF was significantly associated with a reduction in late mortality in all patient groups, although its impact was a little less for those patients who received HCR.

in all patients. Complex PCI was not associated with adverse late outcomes in HCR cases, and the use of multiple arterial grafts did not significantly affect late survival in those patients who underwent CABG.

\section{Cost and Resource Use}

A greater proportion of patients undergoing $\mathrm{CABG}$ required transfusion of blood (HCR $14.0 \%$ vs CABG $28.5 \%, P<.0001$ ) or platelets (HCR $3.9 \%$ vs CABG $8.7 \%, P=.04)$. These increased transfusion requirements in the CABG group did not translate into a higher incidence of reoperation for bleeding (Table 4). The HCR group had shorter hospital lengths of stay than the CABG group.

Accurate cost data were available for those patients treated between 2014 and 2016 who were part of the bundled payment model, whereby providers were reimbursed a single payment for all services provided during a specific episode of care. Mean cost for a bundled payment for a patient receiving CABG $(\$ 47,965 \pm \$ 16,836)$ was comparable to the cost of a patient receiving HCR in whom the MIDCAB and PCI components were performed during the same hospital admission $(\$ 47,245 \pm \$ 9139)$. The mean cost for patients receiving HCR who underwent staged MIDCAB and PCI $(\$ 39,459 \pm \$ 7055)$ was somewhat lower than that of $\mathrm{CABG}$, although this cost differential did not reach statistical significance.

\section{DISCUSSION}

There is a large body of data supporting the short-term benefits of HCR, demonstrating comparable in-hospital outcomes to conventional $\mathrm{CABG},{ }^{8,17,18}$ and, indeed, our analysis further supports these findings. Our results also affirm that HCR is associated with lower perioperative transfusion requirements than CABG. ${ }^{19}$

However, there remains a paucity of data regarding the longer-term outcomes in the HCR cases. A number of 
studies have reported favorable short-term to midterm results of HCR compared with CABG, particularly with respect to survival, with follow-ups ranging up to 5 years. ${ }^{20-23}$ Giambruno and colleagues ${ }^{24}$ have reported good outcome data with HCR for 2-vessel coronary disease with a mean follow-up of $77.82 \pm 41.4$ months. Our results are some of the longest reported follow-up to date on patients undergoing HCR for multivessel (in this case, 2-vessel) coronary disease and confirm excellent intermediate-term survival for appropriately selected patients with double-vessel disease who undergo HCR or CABG (Figure 2).

The SYNTAX trial heralded the era of quantifying the complexity of angiographic coronary disease. ${ }^{25}$ A number of authors have used the concept of a "residual SYNTAX score" after PCI to objectively assess the degree of completeness of revascularization after multivessel stenting, and they have demonstrated the adverse prognostic impact of incomplete revascularization over the short to medium term. ${ }^{26-29}$ A subgroup analysis of the SYNTAX trial has also confirmed that incomplete revascularization is associated with poorer outcomes, particularly after PCI. ${ }^{30}$ More recently, the concept of a "residual SYNTAX score after CABG" has been introduced to quantify the completeness of revascularization attained through surgery. Melina and associates ${ }^{31}$ have demonstrated that the incidence of cumulative major adverse cardiac and cerebrovascular events (MACCE) directly correlates with increasing residual SYNTAX score after CABG and portends a worse outcome at 12 months follow-up.

Our article is thus far one of the first to directly compare residual SYNTAX score after HCR versus CABG for double-vessel disease. Residual SYNTAX score was very low in both of our patient groups, reflecting the completeness of revascularization that was able to be achieved using either technique; this undoubtedly, at least partially, explains the excellent 8-year survival data that we have observed in our HCR cohort.

Dialysis-dependent renal failure is well established as a risk factor for adverse outcomes after cardiac surgery and is one of the single most powerful variables in the Society of Thoracic Surgeons risk calculator for coronary artery surgery. ${ }^{32}$ Our data confirm that end-stage renal disease is indeed a strong independent predictor of late mortality, irrespective of the technique of revascularization uses.

Patients receiving HCR used less perioperative resources than the patients undergoing CABG. These patients not only required fewer transfusions but also had shorter lengths of stay. Despite this, we did not demonstrate a significant hospital cost-saving for HCR cases, especially if the surgical and percutaneous interventions were performed during the same admission. Those patients receiving HCR who had staged PCI did offer some financial saving (\$7786 per patient), although this difference was not statistically significant. One may reasonably expect that the true cost-effectiveness of HCR would become apparent when factoring into the equation the patient's faster recovery time, expedited return to normal activity, and earlier return to work. ${ }^{33}$

\section{Study Limitations}

Our study has a number of limitations to be acknowledged. Our data are derived from a retrospective review in a single institution. A multicenter approach, incorporating a larger sample size, may be more adequately powered to analyze further subtle differences between patient groups, not only for late mortality but also for other MACCE outcomes. Our patients were not randomized to HCR or $\mathrm{CABG}$; the decision as to which revascularization technique to implement was made by a multidisciplinary heart team; therefore, selection bias cannot be eliminated. Nevertheless, the impact of a single practitioner's influence was somewhat diluted by the adoption of the heart team approach; propensity matching also ensured that the HCR and CABG groups were comparable. Our institution has extensive experience with minimal-access robotic-assisted LITA-LAD grafting, as well as with complex PCI techniques. Indeed, the latter may help explain why complex PCI was not found to be an independent predictor of late mortality in our HCR cases. Thus, our results may not be directly generalizable to other institutions that have less experience with robotic-assisted MIDCAB. We used the National Death Index as our primary source for 8-year survival data; this may somewhat underestimate true mortality, ${ }^{34}$ and unfortunately does not provide any information about other MACCE-type end points that would be of interest.

\section{CONCLUSIONS}

Our results confirm that HCR is associated with equivalent perioperative outcomes to CABG for patients with double-vessel coronary disease. Of note, our results also demonstrate that intermediate-term survival is comparable between the 2 groups. Despite requiring fewer perioperative resources than CABG, HCR was not found to be significantly less expensive than traditional surgery, particularly if the surgical and PCI components of the revascularization were performed during the same hospital admission. The excellent short-term and midterm clinical outcomes in these patients support the continued use of a hybrid revascularization strategy for patients with double-vessel coronary disease with appropriate angiographic anatomy.

\section{Conflict of Interest Statement}

M.C.K. is a consultant for Boston Scientific, Cardiovascular Systems Inc, Heartflow, and Medtronic. V.P.S is a consultant for Abbott, Boston Scientific, and Medtronic. All other 
authors have nothing to disclose with regard to commercial support.

The authors thank Sohrab K. Vatsia, MS, and Efstathia A. Mihelis, MBA, for assistance in data collection and management and in the overall preparation of this article.

\section{References}

1. Mohr FW, Morice MC, Kappetein AP, Feldman TE, Stahle E, Colombo A, et al. Coronary artery bypass graft surgery versus percutaneous coronary intervention in patients with three-vessel disease and left main coronary disease: 5-year follow-up of the randomised, clinical SYNTAX trial. Lancet. 2013;381:629-38.

2. Kappetein AP, Head SJ, Morice MC, Banning AP, Serruys PW, Mohr FW, et al. Treatment of complex coronary artery disease in patients with diabetes: 5-year results comparing outcomes of bypass surgery and percutaneous coronary intervention in the SYNTAX trial. Eur J Cardiothorac Surg. 2013;43:1006-13.

3. Parasca CA, Head SJ, Milojevic M, Mack MJ, Serruys PW, Morice MC, et al. Incidence, characteristics, predictors, and outcomes of repeat revascularization after percutaneous coronary intervention and coronary artery bypass grafting: the SYNTAX trial at 5 years. J Am Coll Cardiol Interv. 2016;9:2493-507.

4. Farkouh ME, Domanski M, Sleeper LA, Siami FS, Dangas G, Mack M, et al. Strategies for multivessel revascularization in patients with diabetes. $N$ Engl $J$ Med. 2012:367:2375-84

5. Fihn SD, Gardin JM, Abrams J, Berra K, Blankenship JC, Dallas AP, et al. 2012 ACCF/AHA/ACP/AATS/PCNA/SCAI/STS guideline for the diagnosis and management of patients with stable ischemic heart disease: a report of the American College of Cardiology Foundation/American Heart Association task force on, American Association for Thoracic Surgery, Preventive Cardiovascular Nurses Association, Society for Cardiovascular Angiography and Interventions, and Society of Thoracic Surgeons. J Am Coll Cardiol. 2012;60:e44-164.

6. Kolh P, Windecker S, Alfonso F, Collet JP, Cremer J, Falk V, et al. 2014 ESC/ EACTS guidelines on myocardial revascularization: the Task Force on Myocardial Revascularization of the European Society of Cardiology (ESC) and the European Association for Cardio-Thoracic Surgery (EACTS). Developed with the special contribution of the European Association of Percutaneous Cardiovascular Interventions (EAPCI). Eur J Cardiothorac Surg. 2014;46:517-92.

7. Harskamp RE, Brennan JM, Xian Y, Halkos ME, Puskas JD, Thourani VH, et al. Practice patterns and clinical outcomes after hybrid coronary revascularization in the United States: an analysis from the Society of Thoracic Surgeons adult cardiac database. Circulation. 2014;130:872-9.

8. Rosenblum JM, Harskamp RE, Hoedemaker N, Walker P, Liberman HA, de Winter RJ, et al. Hybrid coronary revascularization versus coronary artery bypass surgery with bilateral or single internal mammary artery grafts. J Thorac Cardiovasc Surg. 2016;151:1081-9.

9. Hemli JM, Darla LS, Panetta CR, Jennings J, Subramanian VA, Patel NC. Does body mass index affect outcomes in robotic-assisted coronary artery bypass procedures? Innovations (Phila). 2012;7:350-3.

10. Hemli JM, Darla LS, Panetta CR, Jennings J, Subramanian VA, Patel NC. Does dual antiplatelet therapy affect blood loss and transfusion requirements in robotic-assisted coronary artery surgery? Innovations (Phila). 2012;7:399-402.

11. Daniel WT, Liberman HA, Kilgo P, Puskas JD, Vassiliades TA, Devireddy C, et al. The impact of clopidogrel therapy on postoperative bleeding after robotic-assisted coronary artery bypass surgery. Eur J Cardiothorac Surg. 2014;46:e8-13.

12. Subramanian VA, Loulmet DF, Patel NC. Minimally invasive coronary artery bypass grafting. Semin Thorac Cardiovasc Surg. 2007;19:281-8.

13. Hemli JM, Henn LW, Panetta CR, Suh JS, Shukri SR, Jennings JM, et al. Defining the learning curve for robotic-assisted endoscopic harvesting of the left internal mammary artery. Innovations (Phila). 2013;8:353-8.

14. Patel NC, Patel NU, Loulmet DF, McCabe JC, Subramanian VA. Emergency conversion to cardiopulmonary bypass during attempted off-pump revascularization results in increased morbidity and mortality. J Thorac Cardiovasc Surg. 2004; 128:655-61.

15. Hemli JM, Patel NC, Subramanian VA. Increasing surgical experience with offpump coronary surgery does not mitigate the morbidity of emergency conversion to cardiopulmonary bypass. Innovations (Phila). 2012;7:259-65.

16. Harris PA, Taylor R, Thielke R, Payne J, Gonzalez N, Conde JG. Research electronic data capture (REDCap)-a metadata-driven methodology and workflow process for providing translational informatics support. J Biomed Inform 2009; 42:377-81.

17. Halkos ME, Walker PF, Vassiliades TA, Douglas JS, Devireddy C, Guyton RA, et al. Clinical and angiographic results after hybrid coronary revascularization. Ann Thorac Surg. 2014;97:484-91.

18. Halkos ME, Liberman HA, Devireddy C, Walker P, Finn AV, Jaber W, et al. Early clinical and angiographic outcomes after robotic-assisted coronary artery bypass surgery. J Thorac Cardiovasc Surg. 2014;147:179-85.

19. Harskamp RE, Bagai A, Halkos ME, Rao SV, Bachinsky WB, Patel MR, et al Clinical outcome after hybrid coronary revascularization versus coronary artery bypass surgery: a meta-analysis of 1,190 patients. Am Heart J. 2014;167:585-92

20. Adams C, Burns DJ, Chu MW, Jones PM, Shridar K, Teefy P, et al. Single-stage hybrid coronary revascularization with long-term follow-up. Eur J Cardiothorac Surg. 2014;45:438-42.

21. Harskamp RE, Vassiliades TA, Mehta RH, de Winter RJ, Lopes RD, Xian Y, et al Comparative effectiveness of hybrid coronary revascularization vs coronary artery bypass grafting. J Am Coll Surg. 2015;221:326-34.

22. Song Z, Shen L, Zheng Z, Xu B, Xiong H, Li L, et al. One-stop hybrid coronary revascularization versus off-pump coronary artery bypass in patients with diabetes mellitus. J Thorac Cardiovasc Surg. 2016;151:1695-701.

23. Xia Y, Katz AN, Forest SJ, Pyo RT, Greenberg MA, DeRose JJ Jr. Hybrid coronary revascularization has improved short-term outcomes but worse mid-term reintervention rates compared to CABG: a propensity-matched analysis. Innovations (Phila). 2017;12:174-9.

24. Giambruno V, Hafiz A, Fox SA, Jeanmart H, Cook RC, Khaliel FH, et al. Is the future of coronary arterial revascularization a hybrid approach? The Canadian experience across three centers. Innovations (Phila). 2017;12:82-6.

25. Sianos G, Morel MA, Kappetein AP, Morice MC, Colombo A, Dawkins K, et al The SYNTAX score: an angiographic tool grading the complexity of coronary artery disease. EuroIntervention. 2005;1:219-27.

26. Schwietz T, Spyridopoulos I, Pfeiffer S, Laskowski R, Palm S, DE Rosa S, et al Risk stratification following complex PCI: clinical versus anatomical risk stratification including "post PCI residual SYNTAX-score" as quantification of incomplete revascularization. J Interv Cardiol. 2013;26:29-37.

27. Capodanno D, Chisari A, Giacoppo D, Bonura S, Lavanco V, Capranzano P, et al. Objectifying the impact of incomplete revascularization by repeat angiographic risk assessment with the residual SYNTAX score after left main coronary artery percutaneous coronary intervention. Catheter Cardiovasc Interv. 2013;82: 333-40.

28. Malkin CJ, George V, Ghobrial MS, Krishnan A, Siotia A, Raina T, et al. Residua SYNTAX score after PCI for triple vessel coronary artery disease: quantifying the adverse effect of incomplete revascularization. EuroIntervention. 2013;8: 1286-95.

29. Farooq V, Serruys PW, Bourantas CV, Zhang Y, Muramatsu T, Feldman T, et al Quantification of incomplete revascularization and its association with five-year mortality in the synergy between percutaneous coronary intervention with taxus and cardiac surgery (SYNTAX) trial validation of the residual SYNTAX score. Circulation. 2013;128:141-51.

30. Head SJ, Mack MJ, Holmes DR Jr, Mohr FW, Morice MC, Serruys PW, et al Incidence, predictors and outcomes of incomplete revascularization after percutaneous coronary intervention and coronary artery bypass grafting: a subgroup analysis of 3-year SYNTAX data. Eur J Cardiothorac Surg. 2012;41: $535-41$.

31. Melina G, Angeloni E, Refice S, Benegiamo C, Lechiancole A, Matteucci M, et al. Residual SYNTAX score following coronary artery bypass grafting. Eur J Cardiothorac Surg. 2017;51:547-53.

32. Shahian DM, O'Brien SM, Filardo G, Ferraris VA, Haan CK, Rich JB, et al. The Society of Thoracic Surgeons 2008 cardiac surgery risk models: part 1-coronary artery bypass grafting surgery. Ann Thorac Surg. 2009;88:S2-22.

33. Head SJ, Milojevic M, Taggart DP, Puskas JD. Current practice of state-of-the-ar surgical coronary revascularization. Circulation. 2017;136:1331-45.

34. Peterss S, Charilaou P, Ziganshin BA, Elefteriades JA. Assessment of survival in retrospective studies: the social security death index is not adequate for estimation. J Thorac Cardiovasc Surg. 2017;153:899-901.

Key Words: coronary artery bypass grafts, hybrid coronary revascularization, robotic-assisted minimally invasive surgery 


\section{SUPPLEMENTARY STATISTICAL ANALYSIS}

Observed covariates at baseline included age, gender, body mass index, diabetes mellitus, cerebrovascular disease, chronic lung disease, dyslipidemia, hypertension, peripheral artery disease, dialysis-dependent renal failure, history of myocardial infarction, heart failure, and left ventricular ejection fraction. To control for these confounding influences, we calculated propensity scores (or the probability of assignment to HCR or CABG) using multivariable logistic regression for each patient. Patients who underwent HCR were matched with patients who underwent conventional $\mathrm{CABG}$ in a $1: 1$ ratio through a nearest neighbormatching algorithm. To exclude bad matches, we instituted a caliper of 0.2 of the standard deviation of the logit of the propensity score. The area under the curve for the receiver operating characteristic of the propensity model was 0.804 . The matched sample included a total of 414 patients evenly distributed in the HCR and CABG groups.

Longitudinal outcomes and long-term survival to 8 years were estimated using Kaplan-Meier analysis and Cox proportional hazard regression. Patient characteristics and outcomes were compared using chi-square, Fisher exact test, Student $t$ test, or Wilcoxon MannWhitney test, as appropriate. A chi-square test was used for categoric variables where the expected value for each cell was 5 or greater; if this assumption was not met, then we used Fisher exact test. Statistical analyses were performed with the IBM Statistical Package for the Social Sciences for Windows, version 22.0 (IBM Corporation, Armonk, NY). 
Unmatched Treated

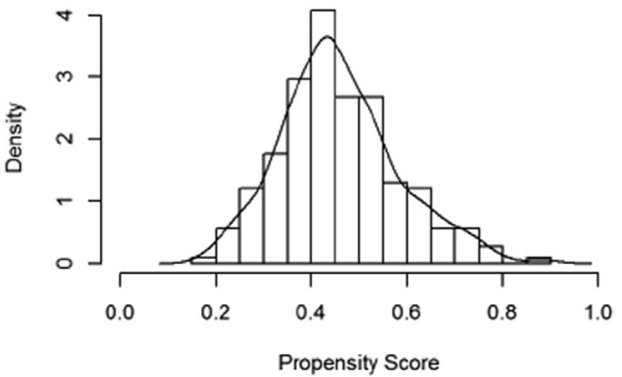

Unmatched Control

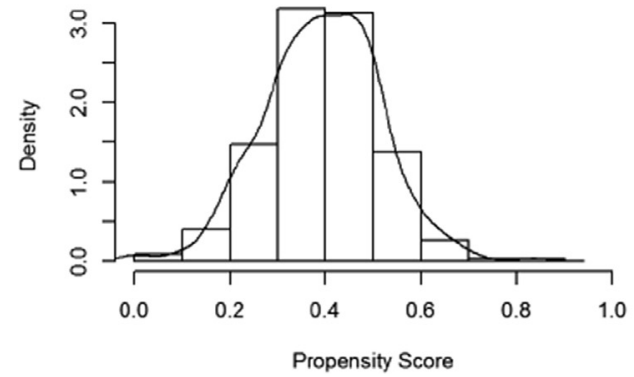

Matched Treated

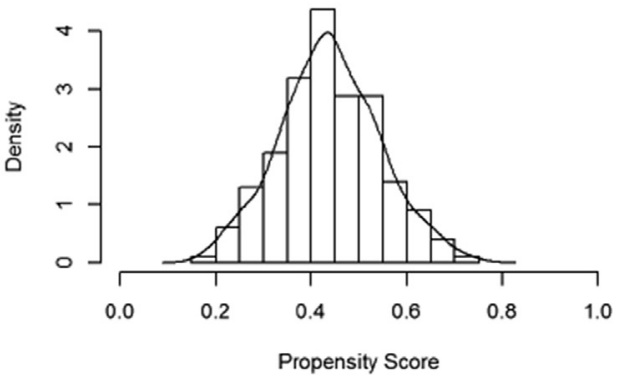

Matched Control

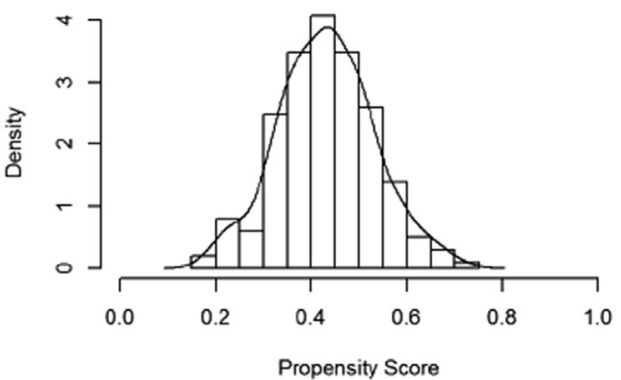

FIGURE E1. Distribution of propensity scores of patients who received HCR ("treated") and patients who received CABG ("control") before and after matching with overlaid kernel density estimate.

\section{Standardized differences before matching}

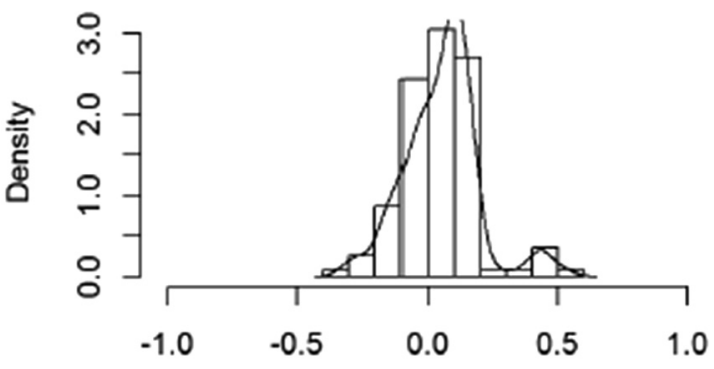

Std. difference

\section{Standardized differences after matching}

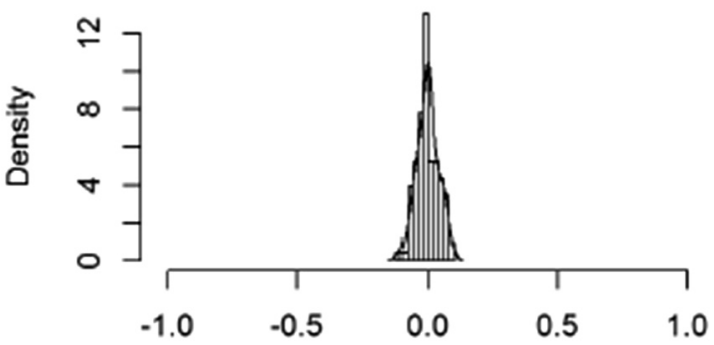

Std. difference

FIGURE E2. Line-plot of standardized differences before and after matching. 


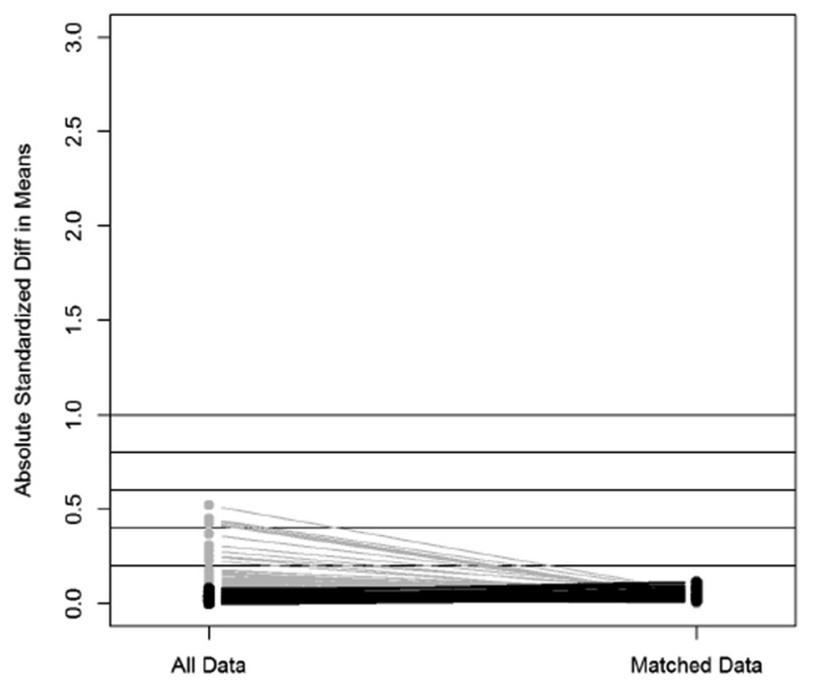

FIGURE E3. Histograms with overlaid kernel density estimates of standardized differences before and after matching.
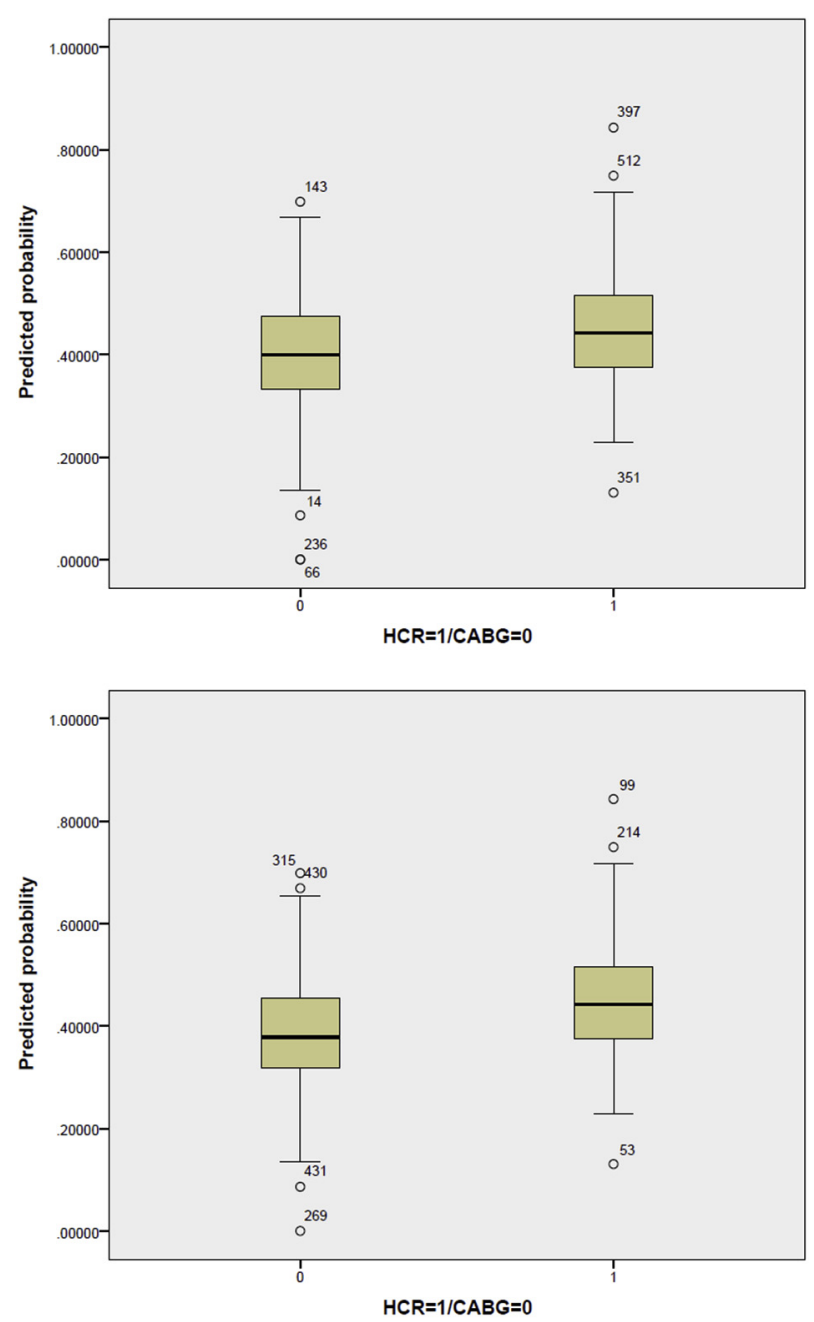

FIGURE E4. Box plot distribution of HCR-CABG propensity scores before (top) and after (bottom) matching. HCR, Hybrid coronary revascularization; $C A B G$, coronary artery bypass grafting. 